\title{
JUEGOS DEL ESPACIO Y ESTRATEGIAS DEL PERSONAJE EN JOSE ANTONIO RAMOS SUCRE
}

\author{
POR \\ CARMEN RUIZ BARRIONUEVO \\ Universidad de Salamanca
}

El sorprendente mundo literario de José Antonio Ramos Sucre (1890-1930) está contenido en pocos títulos. Desde los intentos iniciales de Trizas de papel (1921) y Sobre las huellas de Humboldt (1923), -que luego compila en La torre de Timón (1925)-, su escritura se afianza y depura en El cielo de esmalte (1929) y Las formas del fuego (1929). Es algo admitido que la homogeneidad de su literatura viene dada sobre todo por la disposición de unas constantes simbólicas y de una temática personalísima que remite, en neta imbricación, a su peculiar concepción estética.

No es por tanto gratuita la elección de sus espacios y sus personajes simbólicos pues el autor, en última instancia, es quien confiere esa unidad al personaje y a la obra en esa función de alteridad, de "convertirse en otro" que consiste en definitiva todo hecho estético ${ }^{1}$. Resulta excepcional la capacidad del escritor venezolano para la creación de personajes que van alcanzando a través de sus breves textos un carácter de símbolo, y casi siempre mediante la inclusión de ámbitos antiguos o de prestigiosos o sugerentes entornos. Se podria argumentar que ese autor -José Antonio Ramos Sucre-se convierte de hecho, por mor de su literatura, en un autor ficticio que permanece marcado por sus insoslayables convicciones estéticas. Aun leída someramente su obra, no puede extrañar que su personal escritura aparezcainserta con su peculiar aislamiento en la historia de las letras hispanoamericanas, y la razón reside sin duda en la característica trabazón de esas convicciones. Desde sus comienzos infantiles los clásicos marcan su preferencia, y esa presencia benefactora permanece hasta su muerte en la insistencia de rechazar cualquier exceso. Fernando Paz Castillo

\footnotetext{
${ }^{1}$ En Ramos Sucre existe una conciencia creadora, conciencia de otras conciencias, que abarca esos varios personajes simbolicos; hay una condición estética de crear una obra en la que está implícita una autonomía. Importa sobre todo diferenciar al autor como sujeto físico y al creador de la obra, que como autor, abarca creativamente ese mundo. No hacemos más que recoger algunas ideas desarrolladas por M. M. Bajtín en "Autor y personaje en la actividad estética" en Estética de la creación verbal, México: Siglo XXI Eds., 1985, 19-22.
} 
recuerda que "sus primeros años se deslizaron a la sombra del padre Ramos, erudito rezagado del siglo XVIII, y que los primeros libros que cayeron en sus manos, aún inhábiles para hojearlos, fueron los de Massillon, Bossuet y algunos textos del latín ${ }^{m_{2}}$. También en las cartas a su hermano Lorenzo recuerda esa rígida educación y las experiencias consiguientes con alguna amargura. Pero lo cierto es que tales comienzos hubieron de marcarle para el futuro y que los moderados consejos de lectura, que en las mismas cartas ofrece a Lorenzo, evidencian ese prurito por no dejarse arrastrar por los valores del momento y acudir a los textos imperecederos de los autores consagrados. También puede aducirse esta explicación de sus origenes ante esa obsesiva depuración estilística que le llevaba a aconsejar escribir "con el único adorno de la expresión exacta y suprimiendo cruelmente lo que pueda sonar a discurso", pensando en todo momento que "La palabra debe ser siempre humilde y llana" y que "Es buen escritor el que usa expresiones insustituibles" ${ }^{\prime 3}$. Ha sido muy comentado el hecho de que en esa persecución implacable de un estilo depurado, hiciera desaparecer el que en sus últimas obras4. Pero junto a este clasicismo la nervadura romántica sustenta a quien sólo vive del material de que están hechas las ensoñaciones. En $E l$ cielo de esmalte dirá en frases que pueden considerarse notas autobiográficas: "Yo recataba mi niñez en un jardín soñoliento, violetas de la iglesia, jazmines de la Alhambra. Yo vivía rodeado de visiones y unas vírgenes serenas me restablecían del estupor de un mal infinito"

${ }^{2}$ Véase Fernando Paz Castillo (1973, 10) y César Augusto León. Este último completa: "El tío clérigo había decidido traspasarle todo el caudal de sus conocimientos. De él recibía clases de latín y constante instrucción general. José Antonio estudiaba. Aprendía el doble de las páginas fijadas para su estudio en cada lección. En la biblioteca del tío lera durante largas horas" (12).

${ }^{3}$ Las dos primeras frases corresponden a una carta a Lorenzo Ramos fechada el 26 de marzo de 1921 (Ramos Sucre 1980. De aquí en adelante citaremos por esta edición anotando tan sólo la página). En la misma carta le aconseja una serie de títulos de la literatura universal a través de cuya selección se observa su profundo dominio de lenguas y culturas, para añadir: "El día que hayas leído todo esto poseerás una cultura enorme. Ya ves, no es necesario leer muchos libros, sino los libros característicos de cada nación y de cada época" (451). La última frase que citamos es un aforismo perteneciente a "Granizada" (424).

4 Paz Castillo llamó la atención sobre este hecho y lo achacó a "la pureza, como estricta norma estética, de un estilo personal que se ha formado él mismo, con reglas precisas de gramática latina" $(1973,15)$. Francisco Pérez Perdomo pensó que con esta eliminación logro "un lenguaje más intenso, más cerrado y de mayor perfección formal". Angel Rama se refirió a ello con más precisión haciendo notar que tal supresión procede de su animadversión por el que galicado condenado por Rafael Baralt en su Diccionario de galicismos (1855) y que esta desaparición, como la supresión de los pronombres relativos en general, responde al deseo de "evitar el desarrollo de las oraciones complejas entramadas mediante el uso de frases subordinadas a las principales" manteniendo las copulativas y las frases independientes en una concepción estética de la escritura (Rama, 190-192). 
(133), y también: "Yo frisaba apenas con la adolescencia y salía a mi voluntad de los límites del mundo real" (142), pues como todo sujeto romántico tiene la sensación de vivir en un entorno de escasa realidad, en la percepción dolorosa de pertenecer a dos mundos a la vez ${ }^{5}$. Y sin embargo también su literatura necesita para su comprensión del apoyo del fin de siglo y de cuanto artificio puso en marcha el modernismo; no puede entenderse su prosa poética sin ese paso capital que se produce en la literatura en esa época; son los suyos paisajes de cultura, frases y símbolos que enlazan en su base con esa primera ruptura que en nuestras letras significa el abandono de la racionalidad y de la imitación de lo real para construir la obra de arte. Es decir, la certeza de que la literatura se funda tan sólo en la palabra.

De todo ello se puede deducir que al abordar una obra como la de Ramos Sucre no debe dejarse de lado el cordón umbilical que enlaza la configuración espacial y la elaboración de sus personajes simbólicos. Da la impresión de que ésta es una tarea que se va afianzando a lo largo de sus tres libros. Se trata de espacios imaginarios, literariamente concebidos, de los que dice Gaston Bachelard que no pueden seguir siendo espacios indiferentes entregados "a la medida y a la reflexión del geómetra", porque son espacios vividos "no en su positividad, sino con todas las parcialidades de la imaginación"(28). En este sentido La torre de Timón remite en su título al ámbito de la torre modernista pero es también la puerta del cielo, emblema de la vigilancia y la ascensión, receptáculo captador de la energía lumínica fijada en el centro del mundo (Chevalier-Gheerbrant); a su vez la alusión en el título al nombre de Timón, el filósofo escéptico griego, rebaja el excesivo entusiasmo de esta orientación. Es sabido que Timón (h. 320230) resaltaba la incapacidad de los sentidos y de la razón para conocer la naturaleza de las cosas, señalando tan sólo las apariencias, sobre las cuales no se podra sustentar ninguna certeza. Que Ramos Sucre coincidía con esta apreciación puede observarse en el siguiente aforismo de "Granizada": "La ignorancia nos lleva derecho al escepticismo, que es la actitud más juiciosa de nuestra mente" (423). En éste sentido el "Preludio" (3), o poema inicial de su primera compilación, puede leerse como una queja dolorida del nefasto tiempo en que vivió, pero es evidente también que el poeta se ajusta a una actitud literaria romántica caracterizada por la apetencia de soledad y de ocultamiento en las "vacías tinieblas", a la vez que por una hipersensibilidad ante la vida presente y pasada, ya que cualquier recuerdo es también amenaza; pero hay

- Usamos esta expresión tomada de la obra de Albert Béguin, -El alma romántica y el sueño (1939), México-Buenos Aires, F.C.E., 1954, p. 196-en la que se destaca la dualidad interior del poeta romántico y el valor del sueño y de la ensoñación en la obra literaria. Es sabido que Ramos Sucre conocía el idioma alemán y era buen lector de los románticos de esta lengua, muy especialmente de Goethe, al que cita en varias ocasiones. (Véase Paz Castillo, 1973; Montejo; y especialmente Ludovico Silva, "Ramos Sucre y nosotros" en Revista Nacional de Cultura (1975) 50-72, y en Ramos Sucre ante la crttica, 169 y ss. 
algo más significativo en este texto, y es que nos adelanta la dualidad simbólica que conforma el mundo que abre este preludio; "el movimiento, signo molesto de la realidad, respeta mi fantástico asilo" (3); es decir que la torre o asilo se vincula al anhelo místico de la quietud, y este reducto se escala "de brazo con la muerte", - para encontrar ese reposo o esa permanencia-, en pugna, por tanto, con el constante dinamismo que es signo de lo real. No es tampoco gratuito que la muerte sea "una blanca Beatriz", amada de Dante, que al mismo tiempo proporciona el amor eterno, la belleza suma y la completa quietud, pues ante la muerte se aprecia en Ramos Sucre una ambivalencia que a la vez produce atracción y repulsión. Por todas estas razones este texto parece fundamental para entender el sentido de este libro, - aparte de las tácitas referencias de tipo social que la crítica ${ }^{6}$ señala en la época gomecista- pues la torre es empleada aquí más que en sentido rubeniano ("Torres de Dios poetas") como una sugerencia de lo divino, aunque desacralizando su contenido y remitiendo su propia conciencia artística, y a su propia actitud ante el mundo, que aspira a ser de una serena contemplación escéptica.

El uso de las señales espaciales es intenso en este libro pues construyen un recinto protector que puede estar representado en primer lugar por la casa, porque la casa es un cosmos o primer universo, "la casa alberga el ensueño, la casa protege al soñador, la casa nos permite soñar en paz" (Bachelard 36); ello se observa en "Discurso del contemplativo" donde se traza toda una poética de esa concepción:

Amo la paz y la soledad; aspiro a vivir en una casa espaciosa y antigua donde no haya otro ruido que el de una fuente, cuando yo quiera oir su chorro abundante, ocupará el centro del patio, en medio de árboles que, para salvar del sol y del viento el sueño de sus aguas, enlazarán sus copas gemebundas. Recibiré la única visita de los pájaros que encontrarán descanso en mi refugio silencioson (39).

La descripción de Ramos Sucre se ajusta con bastante exactitud al tópico del locus amoenus tal y como se nos ha trasmitido desde los clásicos latinos; aparecen el árbol, el prado o jardín la fuente o arroyo, la brisa y el canto de las aves (Curtius 273); elementos conjugados con la apacibilidad y el silencio meditativo para el ejercicio de los bienes espirituales en aras de lo inalcanzable. Todo ello vuelve a ser la actualización del tópico clásico del beatus ille. Porque la casa es también, un recinto aislado, "la luz llegará hasta mí después de perder su fuego en la espesa trama de los árboles; en la distancia acabará el ruido antes

\footnotetext{
6 Véanse críticos como Carlos Augusto León, José Ramón Medina, Guillermo Sucre, Cósimo Mandrillo. Fragmentos de estos trabajos están incluidos en Ramos Sucre ante la crítica. Cósimo Mandrillo destaca que su actitud fue la de no participación, actitud que suscribe Angel Rama añadiendo que Ramos Sucre defiende una concepción «democrática» "contra la concepción 'dictatorial'o represiva que llegó a convalidar el positivismo" (183).
} 
que invada mi apaciguado recinto; la oscuridad servirá de resguardo a mi quietud" (39). La casa puede ser también un castillo como en "El canto anhelante" donde "domina un ancho espacio, a la manera del león posado frente al desierto ambiguo" (59). Da la impresión de que cualquier recreación de La torre de Timón necesita uno de estos motivos, ya sea casa, castillo, palacio, torre -De la vieja Italia" (62), "La hija de Valdemar" (61), "El rezagado" (90), "El mensajero" (99), "Los lobos del yermo" (110) pueden ser algunos ejemplos. Siempre aparecen, de un modo u otro, como recintos protectores en los que la confluencia de lo dinámico y de lo apacible, - de la vida y de la muerte, y sobre todo del aniquilamiento que produce la ensoñación-, ejercen especial atractivo. En este sentido nos parece significativo el poema "La casa del olvido" (116-117) donde el locus amoenus queda paliado por la fascinación que ejercen los recintos sugeridores para el ejercicio de los sueños: "El sueño, de semblante lívido y alas funerales, visita el retiro inexpugnable" y "él es la única interrupción del soliloquio vertiginoso"; hay vegetación, flores - "una flor que parece de artificio" (116) - , un estanque, la luna, motivos todos que no contradicen la trabazón del lugar ameno clásico, pero que esta vez es negado por el juego funerario que predispone "a la meditación escrupulosa de la muerte", -es "morada funeral" (117)-, donde el juego de tonalidades amarillas y negras entra dentro del regusto modernista decadentista del color; pero aquí se nos marca más que nada ese carácter simbolico de la confluencia de las cosas vivas y las cosas muertas. Parece ya emblemática del poeta venezolano la construcción peculiar de esos recintos en esta primera compilación de su obra, -que por otra parte Angel Rama consideró summa de su poesía y de su pensamiento bajo la forma de una compilación aparentemente heteróclita (169)- donde un texto como "Sobre la poesía elocuente" ofrece con claridad el instrumento axial de su poética: la expresión mediante imágenes que él identificaba con el símbolo; pero a su vez el empeño por distinguir la elocuencia y la retórica ${ }^{7}$ como "arte de bien decir", frente a la traicionera declamación - que es "retórica defectuosa" - delata su sesgo clasicista:

La imagen es la manera concreta y gráfica de expresarse, y declara una emotividad fina y emana de la aguda organización de los sentidos corporales, [...] y [...] La imagen siempre está cerca del símbolo o se confunde con él, y, fuera de ser gráfica, deja por estela cierta vaguedad y santidad que son propias de la poesía más excelente, cercana de la música y lejana de la escultura (86).

La raíz romántica de su concepción simbólica ha sido observada por la crítica. En el avizoramiento de sus imágenes reside la conciencia de que ésta es

\footnotetext{
${ }^{7}$ Alba Rosa Hernández Bossio elige el término retorica para nombrar la técnica de la escritura de Ramos Sucre, en el sentido de que retorica significa el "conocimiento de los procedimientos espećficos para producir literatura" y añade que "es un poeta que se hizo con el trabajo, la conciencia, el conocimiento teórico sobre gramática y retórica" (12). En definitiva hablar de retórica en este caso no es más que sinónimo de exigencia de escritura.
} 
la única manera de aprehender lo inefable, lo que no es patrimonio de la razón; por eso también dirá en un aforismo que "El hombre ha inventado el símbolo porque no puede asir directamente la realidad" (426), la realidad poética está compuesta de oscuras sugestiones que responden a un modo de sentir las cosas en el que se cruzan orfismo y pitagorismo, palabra y sonido, para construir criaturas en verdad armónicas. Esa armonía que rige la concepción simbólica del espacio le conduce además a utilizar símbolos conectivos como la ventana, elementos expresivos de la receptividad terrena y espiritual sobre la que caben diversas variantes: "El olvido, inexorable centinela, custodia su ventana" ("Miércoles de ceniza" 42); "Siento, asomado a la ventana, la imagen asidua de la patria" ("El episodio de nostálgico" 45); "Desde mi ventana remontada miro a mis pies la ondulación de la floresta, en un ángulo del horizonte, la luz espasmódica del relámpago" "El cruzado" 108). Ventanas y casas, cualquiera que sea su ubicación, suelen remitir a los lugares poblados, bien sea a las aldeas o a las ciudades, pero estos lugares no se contemplan como añoranza, sino como lugar de observación, que comunican a ese sujeto con el mundo en que vive en el doble aspecto físico y espiritual.

Es frecuente también en Ramos Sucre el tópico de la ciudad en ruinas o en decadencia que tanto se usó en el fin de siglo; en "Entrevisión del peregrino" (125) en un marco de crepúsculo violeta y desasosegante vendaval, los árboles presentan una tonalidad negruzca, en los jardines cuelgan restos de floración perdida y los paseantes se mueven entre las ruinas esparcidas por doquier; la atmósfera lleva efluvios letales, “y la despoblación recuenta la visita de las epidemias errabundas, criadas en lejanas riberas inundadas, en el seno de los pantanos cálidos" (125). Tal descripción, que sugiere el marco de destrucción de las guerras medievales, puede compararse con esa visión de las ciudades muertas, comola Venecia de Maurice Barrès (La Mort de Venise 1903), ciudades literarias del fin de siglo en las que el poeta se recrea porque representan la total inmovilidad; la ciudad sólo pierde su agresividad cuando la destrucción la hace inofensiva para siempre. A este respecto Hans Hinterhäuser se refiere a la posibilidad de que estas imágenes respondieran a un desahogo, mediante una fantasía destructiva, de la impotencia de los artistas finiseculares hacia una "nueva era" que escapaba a su dominio. "Destruían unas ciudades que se habían vuel to incomprensibles y hostiles" $\mathrm{y}$ "creaban pálidas contrafiguras de decadencia, en las que pudiesen sublimar su marginación social" (64). Parecida descripción, pero desde una perspectiva más subjetiva aparece en "La ciudad" (97); aquí ese sujeto poético vive en un ámbito de hostilidad - "Yo vivía en una ciudad infeliz", "El sol declinante pintaba la ciudad de las ruinas ultrajadas" -, tan sólo la noche acoge el paso del soñador pero también el mar sobresalta sus sentidos; pasea por una ciudad anticuada y monótona y "El aura prematinal refrescaba esforzadamente mi cabeza calenturienta, desterrando las volaterías de un sueño confuso" (97); todo ello presenta un espacio en el que el concepto de ciudad 
vuelve a unirse al concepto de lo negativo de las cosas; la ciudad agita los sentidos, enferma la imaginación, revuelve el pensamiento; tal vez porque en ella reside lo dinámico de la vida humana, lo que lleva al fanático pragmatismo de los pequeños comerciantes, presos por siempre en las leyes del dinero y de la mezquina vida política; y en la concepción de Ramos Sucre el movimiento desordenado y horizontal siempre es símbolo de imperfección. Por eso son frecuentes las presentaciones duales del espacio de la casa y de la ciudad incluso en los textos en que el subjetivismo se presenta por personajes interpuestos. Así en "El fugitivo" (8) ese sujeto poético busca un recinto protector; lo encuentra primero en el "antro causado por el desarraigo de un árbol", pero ese cobijo resulta únicamente transitorio, para divisar a lo lejos "la lumbre del asilo" donde reside su dios y cuya imagen lo escucha y le sonrie. Del mismo modo que el dinamismo y la ausencia de dinamismo forman una polaridad los lugares abiertos y cerrados, los espacios limitados y los no limitados; la ciudad es en consecuencia el lugar de la destrucción y de la hostilidad. Ello aparece en el más alto grado en "El familiar" (10-11), donde el sujeto poético vive en "el sosiego de una ciudad extinta", "capital de un reino abolido", y habita en un lugar que simboliza una clara variante de la torre, porque observa el exterior desde un balcón - "retiro para el soliloquio y el devaneo"-. La dualidad se afirma al salir a la calle donde encuentra el grupo de héroes difuntos que los jóvenes intentan devolver al reino de la muerte; lo dinámico vuelve a tener un espantoso origen que lo conexiona con el reino de ultratumba. Otros matices presenta "Entonces" (22) en el que el tópico de la ciudad moderna destructora -el "destierro en la ciudad moderna que se atormenta con el afán del oro"- está desarrollado en consonancia con una sensibilidad enfermiza muy cercana a los escritores finiseculares; y el intenso vagar del sujeto poético está ligado a la búsqueda de la niña, que representa la belleza o la poesía. Pero la quietud está unida a la vejez:

Mi mansión será para otros impenetrable roca y para mí firme cárcel. Estoico orgullo, horrenda soledad habré alcanzado. En torno de mi frente flotarán los cabellos grises, grises cual la ceniza de huérfanos hogares (22).

El personaje ha alcanzado así su meta solitaria al replegarse en su espacio, al rechazar cuanto le rodea, pero tras esta construcción simbólica late con claridad el desengaño de quien consideró inútil participar en vida política de su tiempo. Por ello los personajes que surgen en estos textos adoptan una peculiar visión del mundo y están unidos al espacio que voluntariamente los condiciona; ese hablante lírico, inquilino de la torre suele tener como don y maldición la soledad pues "soñador de una imposible justicia" va "quejumbroso y aislado por la vida" ("A un despojo del vicio" 9). Otras veces sumido en el olvido "Esquiva su alma a la mundana agitación, y moderada por el desengaño, vuela como la enlutada golondrina a recogerse en el ambiente místico del templo" ("Miércoles 
de ceniza" 42). Dentro de la misma orientación un texto como "La vida del maldito" (103-104) hace ponderar mejor el juego del espacio y personaje; este sujeto poético ama "el dolor, la belleza y la crueldad", considerando a esta úl tima único y eficaz antídoto contra la propagación del mal por el mundo; se queja de las imágenes persistentes de la vejez y de la enfermedad de sus abuelos y se retira a su mansión aislada, aceptando la única posibilidad de la soledad en un ambiente sombrío y apartado en la ciudad de sus orígenes, donde apenas se entrevén las huellas del progreso humano. Tales convicciones lo llevarán a ejecutar la muerte de su esposa como remedio higiénico para su propia realización. Al final la locura y los deseos de autodestrucción ocupan su tiempo:

Yo quiero escapar de los hombres hasta después de muerto, y tengo ordenado que este edificio desaparezca, al día siguiente de finar mi vida y junto con mi cadáver, en medio de un torbellino de llamas (104).

Se ejercita con plena consciencia en Ramos Sucre, - y este texto es buen ejemplo de ello- esa estética de la crueldad y del mal que dio nacimiento con la poesía de Baudelaire ${ }^{8}$. Pero además de una postura estética consciente hay que encontrar en estos motivos una honda insatisfacción, una raíz romántica, que se va incrementando en su obra hasta su último título, en virtud de esa primera persona aproximativa, a lo literariamente creado.

El primer personaje simbólico que asoma en La torre de Timón es el héroe, ideal humano que encarna las facul tades de nobleza de lo físico y de lo espiritual en el mundo antiguo (sapientia et fortitudo), pero que, al pasar al Renacimiento, adopta los ideales cortesanos tal y como los concibió Baltasar del Castiglione para el caballero de su época (Curtius 256) en la dúctil combinación de los valores de las armas y de las letras, o del uso de la pluma y de la espada. Ya Angel Rama habló del fervor heroico que recorre su obra y que responde a la constante del período gomecista, paradigma también usado por Laureano Vallenilla Lanz para edificar la figura de César democrático (Cesarismo democrático, 1919). Aunque por otra parte esa alusión al heroísmo podría presentar -como bien apunta Rama - una doble significación: "equipararse al ensalzamiento oficial de la historia o afirmarse como una condición constante del hombre, necesaria para enfrentar tiempos adversos y conservar afiladas las espadas para utilizarlas

\footnotetext{
${ }^{8}$ Muchos han sido los críticos que han percibido esta opción de la crueldad como estética: Pérez Perdomo, Guillermo Sucre. Angel Rama señala que el autor fue consciente de la subversión de las reglas del arte en la época de la modernidad y del desplazamiento del bien por el mal en la obra literaria (181). Es evidente que el siguiente aforismo de "Granizada" implica una clara reflexión sobre el tema: "El mal es un autor de la belleza. La tragedia, memoria del infortunio es el arte superior. El mal introduce la sorpresa, la innovación en este mundo rutinario. Sin el mal, llegaríamos a la uniformidad, sucumbiríamos en la idiotez" (426).
} 
en beneficio de una deseada libertad" (180). No queda ninguna duda sobre la postura que adopta el escritor venezolano ante esa perspectiva histórica: impone un ideal que concentra en su seno las más altas virtudes; ante el utilitarismo moderno burgués, el objetivo de la empresa y de la virtud de lo intangible. En un análisis pormenorizado del símbolo del caballero desde su raíz medieval, Cristian Alvarez apunta que viviendo en un mundo en el que dominan los valores materiales y "derrotado eternamente por la realidad histórica, el caballero batalla por la fe, el amor y la justicia, valores ideales e irrealizables, pero absolutamente necesarios. Esa Tocura' por los ideales nobles es la que lleva al caballero a ser un ejemplar único, un solitario" (62). Por ello resulta significativo que uno de los primeros textos de La torre de Timón sea "Elogio de la soledad" donde se intenta justificar este apartamiento solitario introduciendo una voz anónima en primera persona, pero dejando sentado previamente y con carácter general que:

siempre será necesario que los cultores de la belleza y el bien, los consagrados por la desdicha se acojan al mudo asilo de la soledad, único refugio acaso de los que parecen de otra época, desconcertados con el progreso (19).

Lo que el texto desarrolla a continuación es una declaración de principios acerca de ese espacio que conlleva el componente de la soledad, es decir las notas constitutivas de ese aislamiento, que no son las del modernista autosuficiente sino las de la soledad solidaria, pero libre de lazos terrenales explicitada en un largo párrafo en el que la propia voz desgrana sus padecimientos, su sensibilidad y hasta su sentido del deber ("No rehuyo el deber de centinela de cuanto es débil y es bello" 19). Pero el héroe da un paso más hasta identificarse con el escritor hasta el punto de formar parte de una misma sangre; en "Estirpe prócera" explica que la distinción espiritual en una familia puede favorecer la aparición del talento poético y añade que "podrían citarse nombres de poetas que sucedieron a militares y caballeros irreprochables" (414). No bastará sin embargo con la figura simbólica del caballero, que entraña siempre un riesgo de aventura y dinamismo, sino que le resultará necesaria la personalidad del monje o del santo, con su inseparable "celda del estudio", porque en la soledad los santos "tuvieron escala de perfección y puerto de ventura". Otra vez el mismo paradigma medieval como mundo imaginado conlleva el modelo que se añora en consonancia con un recinto protector: "La historia me ha dicho que en la Edad Media las almas nobles se extinguieron todas en los claustros" (20) y se entiende, por exclusión, que aquellos seres en los que no cabe ninguna nobleza son los que desarrollan cómodamente su actividad en el mundo. Por eso resulta casi obligado que uno de los personajes emblemáticos de Ramos Sucre sea este hombre religioso, monje o novicio, que vive "en una celda, y no en medio de árboles frondosos" ("La tribulación del novicio" 32), espoleado por los placeres del mundo y acosado por la carne pero con la certeza de que no es otro su destino; 
por su estado sufre "mayor esclavitud que un presidiario", soporta las tentaciones aunque nada calma su ardor, pues ese asilo presenta la contradictoria condición de lo impuesto y de lo aceptado, concordando en ambas posiciones el ambiguo modo del bienestar supremo y el dolor de su padecimiento. Hay en la figura del monje, más que en la del caballero, un grado más sutil de preferencia porque representa una mayor relación con la cultura que proviene de la heredada imagen del Medievo del clérigo transmisor de la cultura.

Tanto el héroe o caballero como el monje suelen avizorar o contemplar el cielo como lugar deseado; - ya dijo San Isidoro que "se da el nombre de héroes a los hombres que por su valor se hacen merecedores del cielo" (Curtius 253). Y éste es precisamente el título de otro de sus libros: El cielo de esmalte. El cielo como manifestación simbólica de lo trascendente, de lo sagrado, concretado o no en unas creencias religiosas, - pues simplemente puede significar lo absoluto de las aspiraciones del hombre-, el lugar de un posible perfeccionamiento de su espíritu, en el fondo siempre soñado, y siempre inasequible. El lugar de partida vuelve a ser ese locus amoenus que se relaciona con las primeras e inconcretas aspiraciones artísticas de la infancia: "Un ciprés enigmático domina el horizonte de mi infancia"; "Yo me sumergía en un sueño libre de visiones y alcanzaba un olvido total" "El alumno de Violante" 232); o bien "Yo viví perplejo descubriendo las ideas y los hábitos del mago furtivo" ("El valle del éxtasis" 135). -Mago o trovador que produce el canto vuelve a ser otra de las aspiraciones plasmadas en algunos de sus poemas. El mago es el soberbio trasgresor de las normas que recibe admoniciones "de origen celeste" y cuyo destino es también el retiro de la soledad ("La penitencia de mago" 106). El mago y el trovador hacen referencia a la mujer y no la rechazan como el monje, así en "Trance" una "beldad rubia" refiere "las cuitas de un trovador desengañado" (115) de tal modo que el sujeto poético se llega a identificar con ese trovador. $O$ con el bardo "proscrito de la vida" que escapa "a meditar lejos de la ciudad, en medio de ruinas severas, cerca de un mar monótono" ("El romance del bardo" 129). Da la impresión de que es el bardo o trovador ${ }^{9}$ el que hace referencia a espacios más amplios pues no suele estar sujeto a un único lugar, y no existe en este caso la celda, que es la morada del caballero-escritor o del monje. Selvas, bosques, o también ruinas de antiguos castillos son sus recintos, como si el canto no debiera ceñirse tan sólo a lo cerrado.

Son frecuentes en $\mathrm{El}$ cielo de esmalte los espacios abiertos y sugeridores en cuyos textos menudea la constante referencia al cielo. Otra vez la visión dual que domina su concepción vuelve a situar lo negativo en relación con la tierra, es el caso de "la ambición terrestre" que padece el protagonista de "El duende" (138). Pero resultan más significativos los poemas que tienden a ambientarse en espacios naturales abiertos que muchas veces remiten a motivos metapoéticos.

${ }^{9}$ Tanto sobre la figura del santo o monje como la del trovador o bardo hay que tener muy en cuenta los capítulos correspondientes del libro de Cristian Alvarez (97 y ss; 159 y ss). 
Así en "Antífona" ese sujeto poético hace referencia a su infancia y está ligado a un espacio netamente modernista: la selva sagrada de Rubén Dario ("Yo visitaba la selva acústica, asilo de la inocencia, y me divertía con la vislumbre fugitiva, con el desvarío de la luz" 142); la doncella es aquí la expresión de la llamada de la vocación poética ("La doncella clemente se presentó delante de mis pasos a referirme las venturas de una vida señoril, los gracejos y desvios de las princesas en un reino ideal" (142)). Pero esta declaración de intenciones vuelve a tener relación con el título del libro: "una ronda aérea seducía mis ojos bajo el cielo de ámbar". La frecuencia de este término - cielo-que hará referencia a la poesía apresada y plasmada puede verse en muchos otros ejemplos. Así en "El peregrino de la fe" dice: "Mi pensamiento se desvanecía a la vista del cielo de ámbar y de una serranía azul" (148); o "El solitario divierte la mirada por el cielo en una tregua de su desesperanza" "Azucena" 154); o el cielo es el lugar del que proceden o se reciben dolorosos dones; "Había recibido del cielo el presente de una belleza infausta" ("Isabel" 158); "Yo me extasiaba en el ambiente de pureza, a la vista de un cielo de tintes ideales" ("El error vespertino" 193); en "El extranjero", "Se vestía de flores y de hojas para festejar las vicisitudes del cielo" (229); en "Evangelio": "Yo caí de rodillas bajo el cielo radiante" (243). Resulta evidente por los textos señalados que ese cielo se relaciona con claridad con ese sujeto poético que de forma más clara llega a ser un yo en primera persona. La dualidad que conforma los textos de Ramos Sucre se ejercita en un movimiento que en este libro se encamina sobre todo hacia ese espacioidealizado. Ello puede observarse con claridad en "La ciudad de los espejismos" donde a través de ese sujeto se nos ofrecen algunos matices autobiográficos. Pero lo que interesa en especial es esa primera persona que recoge las dolorosas vivencias del monótono vivir cotidianoy del transcurso del tiempo para con un gesto apenas inconsciente abrir esa ventana y señalar que "Una vislumbre desvariada recorría los cielos" (258). Esa primera persona ${ }^{10}$ casi agobiante cumple una función de apresamiento, de atracción de lo que puede ser dicho, es el elemento que transmuta, el más eficaz instrumento para hacer creíble la reescritura de lo contado. Tal vez haya sentido el autor el temor a la frialdad de lo parnasiano, de la mera historia contada, y ese yo instrumental atrae y revitaliza, ejerce y refuerza su visión simbolista del mundo. Y sirve para prodigar las máscaras, para aproximar a los diferentes personajes, para construir con ellos un efecto de diálogo. Parece que en Ramos Sucre siempre hubiera la necesidad de salir del corto espacio que le propiciaba la lírica que le precedió en su intención de hacer vivir las palabras, y para ello, en un sutil artificio de dificultad, se vale del mismo procedimiento de la poesía lírica, el de la primera persona impositiva. Un índice de su opinión pudiera colegirse de una frase inserta en "Ideas dispersas sobre Fausto" de su libro póstumo Los aires del presagio (1960), donde censura a algunos escritores

${ }^{10}$ El uso obsesivo y creciente de esta primera persona en sus textos ha despertado curiosidad y multitud de opiniones. Destacamos las de Guillermo Sucre $(1975 ; 1978)$ y el pormenorizado estudio de Tenreiro. 
que "casi nunca se atreven a hablar de sí mismos y emplean en lugar del yo franco y odioso el se vago e impersonal" (410). Y Ramos Sucre prefiere, es evidente, el subjetivismo que el yo entraña, implicando al sujeto poético en todos y cada uno de los personajes que presenta. Ese yo es todos los personajes simbólicos, pero es también el autor ficticio, y a veces, en el uso de la ambigüedad deja traslucir restos autobiográficos que hacen al propio poeta abarcar todos los personajes a la vez.

Las formas del fuego, de título también enigmático, es para Cristian Alvarez un libro marcado por esa presencia del fuego en las diversas formas, cenizas, humo, hoguera, y añade que "la imagen del fuego, voluble y tornadiza como las llamas, asume distintos símbolos o 'aplicaciones' " (80). Es por tanto un libro signado por la incidencia de esa estética de la crueldad que el escritor había iniciado antes y por los tonos sombríos que desembocan en la destrucción y en la muerte. Aunque también cabría pensar en la purificación que el fuego implica, en su relación con el cielo - - es un don divino-como paso previo, o como purgatorio necesario (Chevalier-Gheerbrant). Se podría hablar por tanto, más que en las compilaciones anteriores, de la mística de la destrucción que todo proceso artístico implica, y los finales de "El castigo" (277), "El emigrado" (278), "El desagravio" (294) o "El retrato" (298) pueden aglutinarse bajo el signo de la purificación. Pero esa purificación hay que entenderla también en relación con ese sujeto poético, aś en "El hidalgo", ese personaje que vive tan sólo de recuerdos de su pasado, ve "en los signos de fuego, presagios del infortunio, descifrados por un visionarioen la sala de un rey mal dito" (310); y es característico que los personajes se carguen de notas de deleznable maldad como en "El protervo" (358-359). Es posibleque el título final, "Carnaval", puedainterpretarse como emblemático de la actitud desarrollada a lo largo del libro. Las máscaras asaltan al sujeto poético que termina entreviendo, por entre la danza carnavalesca, la amenaza de la mujer que representa la atracción del más allá. Es decir la confluencia de lo que - surgido de fuego- ha de morir, y de lo que puede renacer de las cenizas.

\section{OBRAS CITADAS}

Alvarez, Cristian, Ramos Sucre y la Edad Media, Caracas, Monte Avila Eds., 1990:

Bachelard, Gaston, La poética del espacio, México: F. C. E., 1983.

Carrera, Gustavo Luis, "El símbolo en José Antonio Ramos Sucre" en Revista de Literatura Hispánica (1977) [Universidad del Zulia], 10-18.

Chevalier, Jean y Alain Gheerbrant, Diccionario de los simbolos, Barcelona: Herder, 1985.

Curtius, Ernst Robert, Literatura europea y Edad Media Latina, Traducción de Margit Frenk Alatorre y Antonio Alatorre, México-Buenos Aires, F. C. E.: 1955,2 vols 
Hernández Bossio, Alba Rosa, Ramos Sucre. La voz de la retórica, Caracas: Monte Avila Eds., 1988

Hinterhäuser, Hans, Fin de siglo. Figuras y mitos, Madrid: Taurus, 1980.

León, César Augusto, Las piedras mágicas, Caracas: Ed. Suma, 1945.

Mandrillo, Cósimo, "Ramos Sucre. La violencia como sustancia poética" en Revista de Literatura Hispanoamericana [Maracaibo] (1975), 69-85.

Montejo, Eugenio, “Aproximación a Ramos Sucre” en La ventana oblicua, Valencia: Eds. de la Universidad de Carabobo, 1974.

Paz Castillo, Fernando, José Antonio Ramos Sucre, el solitario de la torre de Timón, Caracas: Instituto Nacional de Cultura y Bellas Artes, 1973.

Paz Castillo, Fernando y otros, Ramos Sucre ante la crítica, selección y prólogo de José Ramón Medina, Caracas: Monte Avila, 1980.

Pérez Perdomo, Francisco, "Prólogo" a la Antología poética de José Antonio Ramos Sucre. Caracas: Monte Avila, 1969.

Rama, Angel, El universo simbólico de José Antonio Ramos Sucre, en La crítica de la cultura en América Latina, selección, prólogos de Saúl Sosnowski y Tomás Eloy Martínez, cronología y bibliografía de Fundación Internacional Angel Rama. Caracas: Biblioteca Ayacucho, 1985, 168-216.

Ramos Sucre, José Antonio, Obra completa, prólogo de José Ramón Medina, cronología Sonia García. Caracas: Biblioteca Ayacucho, 1980.

Sucre, Guillermo, La máscara, la transparencia, Caracas: Monte Avila Eds., 1975, 81-87.

Sucre, Guillermo, "Ramos Sucre: Anacronismo y/o renovación" en Tiempo Real 8 (1978), 9-15.

Tenreiro, Salvador, "Para una poética del sujeto en la obra de José Antonio Ramos Sucre" en Escritura 11 (1986), 25-48. 
